\title{
PODERIA SE FAZER HISTÓRIA POR MEIO DOS FILMES?
}

\section{HISTORY COULD BE MADE THROUGH THE MOVIES?}

Lucas Braga Rangel Villela*

ROSENSTONE, Robert A. A história nos filmes, os filmes na história. São Paulo: Paz e Terra, 2010. 264 p.

Vivemos em um mundo midiático, em que os meios audiovisuais fazem parte do cotidiano e tornam-se ferramentas essenciais para compreendermos o passado e o presente. Cada vez mais, registros históricos, práticas culturais, festividades, pessoas públicas e anônimas têm suas imagens e sons fornecidas pelos meios audiovisuais. Assim, é cada vez mais urgente indagar nossa relação com o passado por meio das mídias visuais e investigar como estas tem se consolidado como um importante agente criador de histórias. Esse fenômeno não pode ser deixado de lado pelo historiador interessado na contemporaneidade.

Dentro deste contexto está situado o livro A história nos filmes, os filmes na história de Robert Rosenstone. O autor é professor de História do Instituto de Tecnologia da Califórnia e um dos mais polêmicos estudiosos da relação entre História e cinema. Além de historiador, Rosenstone atua como consultor de roteiros cinematográficos, como no filme Reds, de Warren Beatty, baseado na obra Romantic Revolutionary. Atualmente é editor do periódico Rethinking History: The Journal of Theory and Practice.

No livro em tela o autor, declaradamente pertencente a uma corrente teórica pós-moderna, expressa as angústias e dificuldades de se trabalhar com os filmes como fonte histórica e propõe uma problemática central: a inevitabilidade de, vivendo em um mundo marcado pela presença constante das imagens, expressarmos o conhecimento histórico por meio dos filmes -

\footnotetext{
* Mestrando no Programa de Pós-Graduação em História da Universidade Federal de Santa Catarina (UFSC). Bolsista CAPES/REUNI. E-mail: lucas_rangelvillela@hotmail.com
} 
basicamente por uma série de filmes classificados pelo autor como pertencentes a um 'cinema pós-moderno'. O cinema pós-moderno apresentaria, segundo seus apontamentos, uma ou mais das seguintes características: contariam o passado de forma autorreflexiva; colocariam em primeiro plano a própria construção fílmica; apresentariam uma multiplicidade de narrativas e pontos de vista; a fragmentação da narrativa cinematográfica; utilizariam-se de paródias, humor e hipérboles como expressões do passado; abusariam da diversidade de significados para os acontecimentos narrados; e principalmente, seus espectadores nunca deveriam esquecer que um filme fala sempre do seu tempo de produção.

Para legitimar suas posições o autor faz uma defesa de princípios identificados com teóricos pós-modernos, como Hayden White, alegando que eles estão "tentando trazer a prática da história para o século XXI com muita vitalidade". ${ }^{1}$ Rosenstone afirma que um segmento significativo da população passou a entender os acontecimentos históricos a partir do contato com as mídias visuais e é neste ponto que ele levanta seu principal conceito e argumento: a existência do cineasta historiador. Em sua defesa de uma história contada por imagens, a partir de um 'cinema pós-moderno' e das habilidades de um 'cineasta historiador', Rosenstone divide sua obra (construída a partir de artigos anteriormente publicados em revistas especializadas) em dez capítulos: A história nos filmes; Ver o passado; Drama Comercial; Drama Inovador; Documentário; Contando Vidas; Cineasta/historiador; Interagindo com o discurso; e por fim, Os filmes na história.

Os primeiros dois capítulos introduzem a tese de que seria possível produzirmos o conhecimento histórico a partir de obras audiovisuais, principalmente em relação ao aumento de uma sociedade de visualidade, marcada pela intensa presença dos meios de comunicação como transmissores de informação, narrativas históricas e ocupando um espaço cada vez maior em relação a cultura letrada. Nesses capítulos o autor apresenta uma discussão historiográfica de forma bem construída com diversos autores e abordagens teórico-metodológicas para pensar as relações entre cinema e história, mas não abrindo mão de sua simpatia e pertencimento a correntes pós-modernas. Outro ponto relevante destes capítulos é a aproximação que o autor faz entre a narrativa escrita e a narrativa fílmica, pautando-se em duas principais aproximações, a de que "referem-se a acontecimentos, momentos e movimentos reais do passado, e ao mesmo tempo, compartilham do irreal e do ficcional, pois ambos são compostos por conjuntos de convenções que desenvolvemos para falar de onde nós, seres humanos, viemos". ${ }^{2}$ Nesta parte introdutória, Rosenstone critica um suposto tradicionalismo historiográfico que estaria negando a importância dos filmes como veículo de transmissão de conhecimento histórico Para tanto, aponta diversas características convergentes 
na produção da tradição escrita e da tradição fílmica, de modo a indicar as especificidades de cada mídia de transmissão de conhecimento. Para ele, o historiador deve estar ciente das dificuldades e particularidades que o cinema impõe. Nesse ponto, segundo o autor, é determinante compreendermos que o filme não necessariamente precisa possuir uma fidelidade histórica com o passado, e sim apresentar verossimilhanças e servir como uma nova e alternativa forma de representar o passado, com suas convenções específicas e particularidades técnicas, estéticas e narrativas. Todavia, os filmes pelos quais ele se interessa são os de cunho histórico, não sendo, portanto qualquer filme que se encaixaria em seus postulados.

Rosenstone assevera que o filme histórico opera a partir de diversas convenções e técnicas como as invenções/ficcionalizações, condensações de personagens e de narrativas, compressões temporais, elipses, alterações de sentidos e de narrativas e certos deslocamentos do passado com o fito de apresentar uma interpretação audiovisual da história. Essas características serão o fio condutor dos quatro capítulos seguintes, onde explora as interpretações cinematográficas do passado nos dramas comerciais, dramas inovadores, documentários e cinebiografias.

No terceiro capítulo Drama comercial, Rosenstone apresenta o que ele compreende como 'filmes históricos' e as principais divergências interpretativas entre os historiadores sobre a validade e julgamentos perante os mesmos. $\mathrm{O}$ autor defende que a maioria dos historiadores julgam o valor histórico dos filmes a partir de certos critérios, tais como "a exatidão dos detalhes, a utilização de documentos originais, a adequação da música e do visual ou a aparente conformidade de um ator para interpretar um personagem cuja linguagem corporal, voz e gestos nunca poderemos conhecer a partir dos registros históricos." ${ }^{\prime 3} \mathrm{E}$ nesse ponto questiona: o que esperamos que um filme histórico seja ou faça? Nesse ponto, introduz a sua principal crítica como teórico da relação entre História e cinema: não devemos pensar num filme como um livro transposto para a tela, esperar que ele acerte nos fatos, pois o filme comercial é acima de tudo uma dramatização, uma interpretação, uma encenação do passado por imagens e sons, e acrescentamos, um produto de consumo. Segundo ele, para evitar cair nessas críticas sobre o cinema histórico, dever-se-ia primeiramente melhor estudar como os diretores de filmes históricos vêm trabalhando, para se compreender as restrições dessa mídia, e como o processo de produção implica em diversas censuras, privações e provações. Nesse sentido, afirma que

Está na hora de pôr fim a essa postura defensiva e adotar uma maneira diferente de ver os filmes históricos, sugerir que tais obras já vêm fazendo história, se com a expressão 
"fazer história", indicarmos não uma participação naquele discurso tradicional, mas uma tentativa séria de dar sentido ao passado. ${ }^{4}$

No capítulo intitulado Drama inovador, Rosenstone categoriza um tipo especial de filmes que conscientemente opor-se-ia aos códigos, convenções e práticas de Hollywood, do Drama comercial - gênero já discutido previamente nos capítulos iniciais de sua obra filme histórico experimental ou inovador, também trabalhado na parte final do artigo Historiografia e Historiofotia de Hayden White. ${ }^{5}$ Rosenstone classifica os diretores dessas obras como esquerdistas ou simpatizantes de revoluções e opositores dos enredos comerciais individualistas e capitalistas dos dramas comerciais: "um novo vocabulário para representar o passado na tela, um esforço para tornar a história (dependendo do filme) mais complexa, interrogativa e autoconsciente. ${ }^{\prime 6}$ Como grande exemplo desse tipo de Drama Inovador, Rosenstone analisa o filme de Eisenstein, Outubro, a partir da interelação entre o roteiro do filme e diversas obras sobre a Revolução Bolchevique de 1917.

O capítulo seguinte aborda os filmes documentários, com base no teórico Bill Nicholls . Para o autor o documentário, como a história escrita, ignora a ficção geral no qual o passado pode ser integralmente narrado com começo, meio e fim. Esta aproximação é que acarretaria em uma maior aceitação dos documentários como fonte para a história por parte dos historiadores. Porém esta confiança seria equivocada, pois os filmes documentários compartilhariam de muitos aspectos dos filmes 'de ficção'. Para Rosenstone,

o documentário se refere a um mundo real do passado e, ao mesmo tempo, é sempre posicionado: ideológico e partidário. Mesmo que seja feito inteiramente a partir de tomadas de atualidade ou de outros vestígios do mundo, o documentário nunca é uma 'aula de história' neutra, mas uma habilidosa obra que deve ser interpretada pelo espectador com o mesmo cuidado dedicado à interpretação de um filme dramático. ${ }^{7}$

Para trabalhar exemplos de 'documentários históricos' a partir dos tipos de documentários ${ }^{8}$ introduzidos por Bill Nicholls, o historiador usa como pano de fundo temático a Guerra Civil Espanhola.

O sexto capítulo trata das biografias, e é intitulado Contando Vidas. Robert Rosenstone debate as características das cinebiografias, seu suposto desprezo pela perspectiva histórica e sua apoteose pelo caráter da dramaticidade, 
o que haveria resultado em muitos prêmios da Academia de Artes e Ciências Cinematográficas - o Prêmio Oscar. Nesse capítulo, o autor preocupa-se em realizar um histórico do gênero no cinema e sua relação de convergências e divergências com a biografia literária. Para o autor,

A ficção imposta por um enredo, o uso criativo dos fatos, a tradução necessária para tornar a vida compreensível e interessante - todos esses elementos que fazem parte da escrita biográfica tradicional (e do romance histórico) também marcam a cinebiografia (no qual parte da tradução envolve o uso da mídia visual e do som). ${ }^{9}$

O capítulo mais problemático é o sétimo, Cineasta/historiador, no qual o autor afirma que alguns cineastas realizam trabalhos sobre História tão bons, ou melhores do que muitos historiadores profissionais. Embora a esta associação não seja recente (já havia sido debatida em seu artigo História em Imagens/ História em Palavras, assim como no artigo de Hayden White, Historiografia e Historiofotia), a novidade parece ser uma ênfase em se obter por meio do cinema o que muitos historiadores rechaçaram no âmbito da História, isto é, a possibilidade de se realizar uma 'história pós-moderna'. Segundo Rosenstone:

Todos [historiadores e cineastas] parecem obcecados e oprimidos pelo passado. Todos continuam voltando a tratar do assunto fazendo filmes históricos, não como uma fonte simples de escapismo ou entretenimento, mas como uma maneira de entender como as questões e os problemas levantados continuam vivos para nós no presente. ${ }^{10}$

Desse modo, para ele, o historiador seria

[...] alguém que dedica uma parte significativa da sua carreira a criar significado a partir do passado, independentemente da mídia/linguagem. Ao fazer isso, os diretores tornam o passado significativo, no mínimo, de três maneiras diferentes - criam obras que visualizam, contestam $e$ revisam a história. ${ }^{11}$ (grifos nossos).

Ainda que pensar a produção de conhecimento histórico por meio do cinema seja algo estimulante, as simplificações de que Rosenstone lança mão para defender seus pontos de vista, causam bastante incômodo. A pressa e superficialismo em definir questões teóricas importantes, e por em dúvida por meio do cinema as diferenças entre História e drama ou ficção parecem mais 
um requentamento de posicionamentos teóricos das décadas de 1980 e 1990 do que uma contribuição original ao estudo das relações entre História e cinema.

Os dois últimos capítulos são conclusivos, sendo o oitavo capítulo, Interagindo com o discurso, um exemplo de como trabalhar temáticas históricas, como o Holocausto, e de como poderiam ser ampliadas a partir do uso de um conjunto de filmes, seja documentários, dramas comerciais, biografias ou dramas inovadores; aqui mais uma defesa frágil e difícil de ser sustentada: a de que esta intertextualidade (ou podemos tratar de relações interfílmicas) visual possibilita por si só preencher lacunas do conhecimento histórico que a tradição escrita não permite. O último capítulo, Os filmes na história, é um reforço da tese principal do livro, a partir da própria experiência do autor como historiador, crítico de cinema, consultor cinematográfico, biógrafo e defensor da historiofotia de Hayden White. Ao terminarmos o livro, pesamos os argumentos e podemos nos questionar: seria possível fazer História a partir dos filmes?

Sem dúvida é importante pensarmos o cinema como um agente de construção e preservação da memória coletiva dada a riqueza deste material para o conhecimento histórico e para as pesquisas de historiadores. Porém, contêm linguagens, desenvolvimentos, formas de expressão, meios e objetivos absolutamente distintos. Dessa forma questionamos: seria possível um cineasta, utilizando-se exclusivamente da linguagem cinematográfica, produzir conhecimento histórico? Se flexionarmos a História a ponto de ela se confundir com o relato ficcional, sim. Mas talvez possamos tomar as provocações lançadas por Rosenstone como um estímulo para refletir sobre as possibilidades de nós historiadores produzirmos, a partir de nosso suporte teórico-metodológico, História por meio dos filmes.

\section{NOTAS}

1 ROSENSTONE, Robert A. A história nos filmes, os filmes na história. São Paulo: Paz e Terra, 2010. p. 16

2 Ibidem, p. 14.

3 Ibidem, p. 57.

4 Ibidem, p. 61-62.

5 WHITE, Hayden. Historiografia e Historiofotia. American Historical Review, 93, n. 5, dezembro, 1998. p. 1193-1199.

6 ROSENSTONE, Robert A. Op. cit., p. 82.

7 Ibidem, p. 111-112.

${ }^{8}$ Os tipos apresentados por Bill Nicholls são: expositivo, observacional, participativo, reflexivo, poético e performativo. Que tipos de documentários existem? In: NICHOLLS, Bill. Introdução ao documentário. Campinas: Papirus, 2005. 
${ }^{9}$ ROSENSTONE, Robert. Op. cit., p. 139.

${ }^{10}$ Ibidem, p. 173-174.

${ }^{11}$ Ibidem.

Resenha recebida em junho de 2012. Aceita em agosto de 2012. 